\title{
ENFERMAGEM FORENSE: UMA ESPECIALIDADE A CONHECER
}

\author{
Karen Beatriz Silvaํㅜ, Rita de Cássia Silva²
}

\begin{abstract}
RESUMO: O objetivo é relatar como ocorre a atuação da enfermagem forense nos Estados Unidos da América. Esta especialidade é amplamente debatida pelas enfermeiras norte americanas, porém ainda é pouco conhecida por enfermeiras brasileiras. A atuação de enfermagem forense ocorre em locais os mais diversos, desde hospitais a tribunais de justiça, em serviços hospitalares e/ou na comunidade. Contribui em comitês de ética de serviços de saúde, nas atividades educativas para indivíduos ou grupos com comportamentos de risco, abuso de álcool e drogas e em organização de campanhas contra a violência. A ênfase na educação preventiva permite que a enfermeira se destaque dentre os demais profissionais envolvidos, em especial, por sua atuação junto à vítima, como responsável em realizar exames minuciosos e coletas de evidências sem contaminação, fatores indispensáveis para sucesso da investigação forense. A atuação das enfermeiras forenses facilita a aproximação com as vítimas e estabelece relações de confiança entre os que atuam nas áreas da justiça, facilitando a cooperação com o exame forense.
\end{abstract}

PALAVRAS-CHAVE: Enfermagem forense; Enfermagem; Violência.

\section{FORENSIC NURSING: A SPECIALTYTO BE KNOWN}

\begin{abstract}
The aim is to state how the practice of forensic nursing occurs in the United States of America. This specialty is widely discussed among north american nurses, but it is less known among brazilian nurses. Forensic Nursing practice occurs in various places, from hospitals to justice tribunals, in hospital services and or in the community. It contributes with health services Ethical Committees, with educational activities to individuals or groups in risk behaviors (drugs or alcohol abuse) and organizing campaigns against violence. Once there is an emphasis in the preventive education, nurses could act in highlights when comparing to other involved professionals, specially regarding the practice with the victim, as the responsible to take detailed exams and gathering contamination evidences, which are fundamental to the forensic investigation. Forensic nurses' practice enables the bonding with the victims and establish trust relationships among the ones who work in the justice field, fostering collaboration with the forensic examination.
\end{abstract}

KEYWORDS: Forensic nursing; Nursing; Violence.

\section{ENFERMERÍA FORENSE: UNA ESPECIALIDAD A CONOCER}

RESUMEN: El objetivo es relatar como ocurre la actuación de la Enfermería forense en los Estados Unidos de América. Esta especialidad es ampliamente debatida por las enfermeras norteamericanas, sin embargo, todavía es poco conocida por enfermeras brasileiras. La actuación de Enfermería forense ocurre en locales de lo más diversos, desde hospitales a tribunales de justicia, en servicios hospitalarios y/u en la comunidad. Contribuye en comités de ética de servicios de salud, en las actividades educativas para individuos o grupos con comportamientos de riesgo, abuso de alcohol y drogas y en organización de campañas contra la violencia. El énfasis en la educación preventiva permite que la enfermera se destaque dentro de los demás profesionales envueltos, en especial, por su actuación junto a la víctima, como responsable por realizar exámenes minuciosos y colectas de evidencias sin contaminación, factores indispensables para suceso de la investigación forense. La actuación de las enfermeras forenses facilita la aproximación con las víctimas y establece relaciones de confianza entre los que actúan en las áreas de la justicia, facilitando la cooperación con el examen forense. PALABRAS CLAVE: Enfermería forense; Enfermería; Violencia.

\footnotetext{
${ }^{1}$ Enfermeira psiquiatra. Especialista em Enfermagem Psiquiátrica e Saúde Mental. Mestre em Prática Avançada de Saúde do Adulto. Mestre em Enfermagem Forense. Doutoranda em Psicologia pela Capella University, Minnesota-Estados Unidos.

${ }^{2}$ Enfermeira. Especialista em Metodologia da Assistência de Enfermagem. Especialista em Bioética. Mestre em Educação, área de concentração Gestão de Instituição de Ensino. Coordenadora do Serviço de Enfermagem do Hospital Universitário Cajuru da Pontifícia Universidade Católica do Paraná-PUCPR. Coordenadora do Curso de Enfermagem em Emergência da PUCPR. Docente de Administração dos Serviços de Enfermagem da PUCPR.
}

Autor correspondente:

Karen Beatriz Silva

14829 Skip Jack Loop - 34202 - Bradenton-Flórida-USA

Recebido: 04/04/09

E-mail:ksilva@keiseruniversity.edu

Aprovado: 10/09/09

Cogitare Enferm 2009 Jul/Set; 14(3):564-8 


\section{INTRODUÇÃO}

O aumento global da violência desencadeou necessidade de preparo de profissionais da área da saúde na educação preventiva de violência interpessoal e detecção de sinais de vitimização. A enfermagem gradualmente ganha espaço e reconhecimento na área forense, devido ao seu amplo desempenho no cuidado individual e coletivo.

A ciência forense trata de quaisquer assuntos relacionados à lei perante o Tribunal de Justiça. Importante destacar que o termo forense ganhou maior especificidade ao ser incluído nas áreas de atuação profissional relacionadas à saúde como de enfermagem, medicina, odontologia e outras ${ }^{(1)}$.

A enfermagem forense nos Estados Unidos e em outros países, como Canadá, China, Itália, Inglaterra, tem sido praticada rotineiramente, quando o Enfermeiro examina, coleta evidências e presta cuidados a vítimas de violência. Esses cuidados são prestados por meio da observação clínica contínua do estado biopsicossocial dos indivíduos. Este campo de atuação da Enfermagem só veio a ser reconhecido como uma especialidade de enfermagem em 1992, por meio da criação da International Association of Forensic Nursing-IAFN, fundada por 72 enfermeiras norte americanas que se dedicavam a exames de perícia em vítimas de abuso sexual e estupro ${ }^{(2)}$. A sede atual, em New Jersey-EUA, é encarregada de rever e regulamentar a prática da enfermagem forense internacional, bem como incentivar a pesquisa, o treinamento e o desenvolvimento dessa atividade em países onde a violência alcança altos índices.

Segundo a IAFN, a especialidade é definida como a aplicação da ciência da enfermagem ao público e à justiça; a aplicação relaciona-se aos aspectos forenses do cuidado à saúde combinado com a formação biopsicossocial da enfermeira na investigação científica da morte e/ou tratamento do trauma de vítimas e agressores, atividades criminais, acidentes traumáticos e abuso físico, emocional e sexual ${ }^{(2-3)}$.

Vários países já implantaram e/ou implementaram a enfermagem forense como uma especialidade da Enfermagem como Japão, Canadá, Austrália, Inglaterra, Peru, Quênia, Coreia, Índia, Jamaica, Suécia e Itália. Em outros, como o Brasil, está em fase de desenvolvimento. Na $13^{\circ}$ Assembleia Anual Científica de Enfermagem Forense, patrocinada pela IAFN, o prêmio internacional de enfermagem forense foi entregue a enfermeiras brasileiras que desenvolvem um projeto no Brasil com o objetivo de buscar o envolvimento da enfermeira nesta especialidade e a conquista de campo de atuação na área forense.

Uma das autoras deste artigo, brasileira, vem desenvolvendo a prática da enfermagem forense no Estado de New Jersey-EUA e devido à importância dessa temática e a sua pouca inserção entre os enfermeiros brasileiros e nos currículos de enfermagem, sentiu-se motivada a escrever este artigo cujo objetivo é relatar como ocorre a atuação da enfermagem forense nos Estados Unidos da América.

\section{A ENFERMAGEM FORENSE NOS EUA E NO BRASIL}

Nos Estados Unidos, a cada ano, mais de 200 mil homens e mulheres acima de 13 anos de idade são vítimas de violência sexual( ${ }^{(4)}$. Registros mostram que 1 em 4 meninas e 1 em 6 meninos serão vítimas de abuso sexual ou estupro antes de completar 18 anos de idade. Em uma média de 7 a cada 10 casos, o agressor é conhecido da vítima ${ }^{(5)}$. Aproximadamente $61 \%$ dos casos de estupros não são reportados à polícia e dentre os 39\% reportados a percentagem de chance de que o agressor confesse é de $16.3 \%{ }^{(6)}$.

As vítimas desta realidade são atendidas, naquele país, dentre outros profissionais, por enfermeiras forenses que executam perícias em casos de violência doméstica, abuso sexual e estupro. Para se qualificar como perito nesses exames, a enfermeira deverá possuir no mínimo 2 anos de experiência na prática assistencial e submter-se a treino de 40 horas com treinamento técnico de coleta de evidências e fotos forenses, revisão de leis locais, revisão de literatura, prática supervisionada em mulheres voluntárias. Nos casos de perícias em adultos, o requerimento mínimo e a execução de 10 exames ginecológicos supervisionados por um instrutor qualificado.

A prática da perícia tambémm pode ser ampliada e aplicada ao exame post-mortem ou in vivo; em crianças com até 13 anos incompletos e adolescentes/ adultos - considerados aqueles com mais de 13 anos; 0 treinamento e o exame são específicos à idade. A perícia pode se estender ao agressor e suspeito para coleta de DNA e outras evidências necessárias.

Estes exames são feitos em hospitais e/ou locais de escolha da vítima, que poderá ir por vontade própria ou conduzida pela polícia. Após a triagem, pela 
emergência, é decisão exclusiva da vítima maior de 13 anos a atuação de um grupo de profissionais também chamados de Sexual Assault Response Team-SART. O grupo é composto por enfermeiras forenses especializadas em exames de perícia, detetives para investigação do caso e uma voluntária treinada para dar à vítima suporte emocional e informações oferecidas pelos serviços disponíveis de apoio às pessoas em situação de violência.

Com exceção das voluntárias de suporte à vítima, a enfermeira é contratada como profissional liberal e é remunerada por caso atendido. Os oficiais da justiça, preferencialmente dos distritos onde trabalham, são assalariados e desempenham outras funções além de fazer parte do SART. Somente a enfermeira forense coordenadora do programa SART é funcionária integral da promotoria pública.

Nos Estados Unidos, a IAFN formulou um protocolo padronizado para a perícia em vítima de abuso sexual e/ou estupro naquele país ${ }^{(2)}$. A padronização ainda não é efetiva em alguns países devido às diferenças econômicas e políticas que envolvem a prática de enfermagem forense e recursos para exames.

Neste caso, as etapas da perícia são efetuadas após consentimento assinado da vítima antes do início e após o consentimento verbal durante do exame. A vítima tem direito de mudar de ideia a qualquer momento, desistindo de continuar no processo. A perícia completa é constituída de um questionário sobre o ocorrido e exame físico minucioso, coleta DNA, investigação, documentção e fotos das lesões corporais, externas e internas, incluindo exame com luz ultravioleta para visualização de substâncias que contêm proteína, como o sêmen ${ }^{(7)}$. Segue com exames de cavidade oral e genitália, com auxílio de colposcópio, anexado a câmera digital e computador, os quais aumentam e gravam a imagem em cores. Roupas também são coletadas para exame forense de investigação de DNA e fibras. Urina e sangue são coletados somente em caso de suspeita de ingestão involuntária de drogas.

Inicialmente, nas situações de estupro, a vítima é submetida a teste de gravidez antes do exame de perícia. No caso de resultado positivo ela é encaminhada para obstetra e em caso negativo é oferecido o tratamento para contracepção de emergência. O tratamento profilático, após completar o exame de perícia, envolve a vacina contra hepatite e antibióticos que previnem doenças sexuais.
Com autorização por escrito, as vítimas são contatadas por telefone, alguns dias após a perícia, pela enfermeira coordenadora do programa, para apoio emocional e avaliação dos serviços prestados pela enfermeira forense, oficial da justiça e voluntária.

Em alguns casos a enfermeira examinadora é requerida a testemunhar como perita nos processos legais no tribunal de justiça, portanto, é indispensável o arquivo da documentação detalhada dos exames da vítima e outras anotações, já que alguns processos podem levar anos até chegar na fase do depoimento profissional.

A prática de enfermagem forense não se limita somente a exames de perícia em vítimas de abuso sexual e estupro: estende-se a outros campos da ciência forense, como a investigação de morte.

Neste caso, o exame do corpo e do local do crime são realizados, avaliados pela enfermeira forense, que tem o conhecimento para tal prática. Observa com cuidado detalhes que podem auxiliar a equipe, em especial o médico legista, na descoberta do que levou o indivíduo à morte e a possível hora do óbito. O conhecimento da anatomia e fisiologia do corpo humano, adicionado ao estudo forense, facilita a visão mais acurada do contexto geral da situação de morte do indivíduo. É importante destacar que o foco principal da enfermeira está voltado à causa e mecanismo da morte, deixando as investigações criminais, descoberta das causas e circunstâncias aos profissionais competentes no assunto.

Há outras áreas de abrangência dessa especialidade como educação preventiva e de reabilitação em serviços de emergência, unidade de terapia intensiva, pediatrias, escolas, saúde comunitária, psiquiatria, penitenciárias, manicômios judiciários e outros. Contudo, a enfermeira forense deverá receber treinamento específico para atuar nessas áreas.

Enfim, a atuação de enfermagem forense ocorre em locais diversos, desde hospitais ao tribunal de justiça, como consultora em casos em que há suspeita de abuso e negligência, em serviços hospitalares e na comunidade. Contribui, assim, em comitês de ética de serviços de saúde, nas atividades educativas para indivíduos ou grupos com comportamentos de risco, abuso de álcool e drogas e na organização de campanhas contra a violência.

Assim, pode-se afirmar que a enfermeira forense possui conhecimento para realizar o trabalho nessa área, que carece de profissionais preparados. Além disso, a ênfase na educação preventiva permite que ela se 
destaque entre os demais profissionais da área de justiça. Em especial, por sua atuação junto à vítima, como responsável em realizar exames minuciosos e coletas de evidências sem contaminação, fatores indispensáveis para sucesso da investigação forense.

A atuação das enfermeiras forenses facilita a aproximação com as vítimas e estabelece relações de confiança entre os que atuam nas áreas da justiça, facilitando a cooperação com o exame forense.

\section{A ENFERMAGEM FORENSE NO BRASIL}

No Brasil, a enfermagem forense ainda é pouco conhecida e com raras atuações como especialidade. Embora muitos profissionais trabalhem com vítimas de violência, não existem ainda programas específicos de adequação nessa área.

Iniciativa de divulgar essa especialidade tem sido desenvolvia na Pontifícia Universidade Católica do Paraná-PUCPR, onde foi apresentado ao corpo docente e discente do Departamento de Enfermagem um seminário durante a Semana da Enfermagem em maio de 2006. A repercussão do evento foi encorajadora e refletiu na demanda dos alunos em conhecer mais sobre o tema, incluindo este conteúdo programático nas disciplinas de saúde da família.

Ainda em 2006, no curso de Pós-Graduação de Enfermagem em Emergência na PUCPR, ofereceuse 15 horas de disciplina de Enfermagem, com conteúdos de deteç̧ão de lesões sugestivas de violência, educação e tratamento das vítimas e agressores. O objetivo é treinar enfermeiros na detecção de lesões físicas e psíquicas, para evitar que possíveis vítimas sejam ignoradas ou passem despercebidas devido à falta de habilidade do pessoal do serviço de saúde. Outro objetivo com o treinamento é capacitar o enfermeiro a notificar às autoridades qualquer caso suspeito de violência.

A enfermagem forense vem sendo divulgada em seminários nas universidades locais (PUCPR, UniBrasil, Faculdade Evangélica do Paraná-FEPAR), Programa Mulher de Verdade em Curitiba-PR, em palestra no Instituto Médico Legal de Curitiba.

\section{CONCLUSÃO}

A atuação da enfermeira forense é bastante diversificada, incluindo exames minuciosos para coleta de evidências, detecção e tratamento de lesões e traumas em vítimas de abuso físico, emocional ou sexual, estupro ou morte e apoio emocional às vítimas e familiares. Examinar, reconhecer, coletar e preservar são fatores essenciais na prática da enfermagem forense, assim como educar a população contra a violência interpessoal.

Considerando que um exame físico completo pode levar até 4 horas, a enfermeira perita dedica-se a fazer um exame amplo e completo na vítima, estando preparada para ser questionada sob o ponto de vista jurídico, estreitando assim a margem de questionamentos da sua prática em tribuna, se for necessário. Em caso de óbito, a enfermeira forense atua na investigação da possível causa da morte, preservando evidências físicas, investigando o corpo, o local onde foi encontrado, atenta aos detalhes importantes para o laudo.

O trabalho da enfermeira forense não se limita somente aos exames e coletas de evidências, mas também se estende ao atendimento de pessoas envolvidas em qualquer forma de violência e negligência, incluindo vítimas de tráfico humano, de acidentes, de erros médicos e de cultos religiosos.

Considerando os benefícios já citados da prática profissional da enfermagem forense aos peritos, além de poupar a sobrecarga de trabalho, as inevitáveis falhas no exame da perícia, que podem causar perda de credibilidade nos depoimentos requeridos por advogados de defesa e promotores. Além disso, é preciso considerar os benefícios às vítimas que são examinadas minuciosamente e aos falsamente acusados, o que não é incomum. Recomenda-se aos conselhos de enfermagem e à Associação Brasileira de Enfermagem-ABEN instituir a enfermagem forense como uma especialidade que merece programa de treinamento e negociações para campo de trabalho.

Visto que a violência é um problema global, sugerimos às escolas de enfermagem que considerem a inserção nos currículos de conteúdos que englobem detecção de sinais de violência e proporcionem ao corpo discente trabalho preventivo na comunidade, educando jovens nas escolas e usuários nos centros de saúde sobre temas que abordam todos os tipos de violência.

\section{REFERÊNCIAS}

1. Lynch VA. Forensic nursing. Colorado: Mosby; 2005.

2. International Association of Forensic Nursing. Forensic nursing. [acesso em 2006 Jul 05]. Disponível: http:// www.iafn.org/

3. Hoyt KS, Warner CG. Topics in emergency medicine. 
[periódico online]. 2005 [acesso em 2007 Dez 17] 27(1): 1-2. Disponível: http://www.nursingcenter.com/library/ JournalArticle.asp?Article_ID=579054

4. Bureau of Justice Statistics. National Crime Victimization Survey 2002 [acesso em 2007 Dez 17]. Disponível: http:/ /www.ojp.usdoj.gov/bjs/

5. Ringel C. Criminal victimization 1996: Changes 1995-96 with Trends 1993-96. Washington, D.C.: Bureau of Justice Statistics, U.S. Department of Justice; 1997.

6. Bureau of justice statistics. National Crime Victimization Survey 1999. [acesso em 2007 Dez 17]. Disponível: http:/ /www.ojp.usdoj.gov/bjs/

7. Marshall S, Bennet A, Fraval H. Locating semen on live skin using visible fluorescence. [acesso em $2006 \mathrm{Jul}$ 05]. Disponível: http://www.forensic.co.kr/bvda/ semen_fluo.html 